\title{
Synthesis and Low Thermal Characterization of Local Soil Based-Building Adobe
}

\author{
Weerapol Namboonruang \\ Department of Civil Technology and Architecture, Faculty of Science and Technology, Muban Chombueng \\ Rajabhat University, Ratchaburi, Thailand \\ Email: bannork_civil@hotmail.com
}

Received February 2015

\begin{abstract}
This work studies the mechanical properties of the soil cement brick and soil cement brick mixed with fly ash from the east of Thailand, Rayong province. The purpose is to develop the new low cost materials used in the local area of Thailand. Results show that the average of the compressive strength and the modulus of rupture (MOR) of soil cement brick mixed with Eastern Rayong fly ash are lower than those of non-fly ash soil cement brick. Also both properties values increase with increasing cured time. However, the thermal conductivity shows the decreasing trend with increasing fly ash content. By conclusion, considered by mechanical properties show that soil cement brick mixed with an Eastern Rayong fly ash can efficiently produce as the structural clay loadbearing tile.
\end{abstract}

\section{Keywords}

\section{Rayong Fly Ash, Compressive Strength, Flexural Strength, Low Thermal Conductivity}

\section{Introduction}

Nowadays, the materials used in the dwelling construction are expensive compared with present economics. This is due to the inflation of material and production costs which directly effect to the reinforced concrete price. Thus, it is necessary to search for the new material which qualifies all functions such as engineering properties, low energy consumption and also being less environmental effect. So, these are the idea to mix fly ash, which is the residual of coal using in the power plant, with soil cement brick. Reports show that the demand of coal to use in the power plants of Thailand in 2011 is approximately 38 million tons [1].

This could generate a number of fly ash considered as dust pollution. Thus, this work will study the possibility of mixing fly ash from power plant with the local soil cement to improve the properties of the brick [2]-[4]. It has been reported that fly ash can improve the properties of cement in functions of the compressive strength and other properties [5]-[8].

Also using fly ash instead of Portland cement can directly reduce the pollution due to the Portland cement 
production which relates to the global warming problem in the present day. Therefore, the conventional method of brick production such as energy consumption and green house gas emission and their dangerous impacts on the environment [9]-[13].

\section{Materials and Methodology}

\section{Study Area and Sampling of Specimens}

The Ratchaburi local soil is mixed with Portland cement and fly ash from the Rayong power plant situated in the east of Thailand. The Portland cement type 1 at constant ratio of $5 \%$ of dry soil weight is mixed by varying fly ash contents of $3 \%, 5 \%, 10 \%, 15 \%, 20 \%, 25 \%, 30 \%, 35 \%, 40 \%$ and $45 \%$ at ratios of water to powder (W/P) $0.1650,0.1963,0.2275,0.2588,0.2900,0.3213,0.3525,0.3838,0.4150$ and 0.4463 respectively.

These materials with dimensions of $125 \mathrm{~mm}$. in width, $100 \mathrm{~mm}$. in thickness and $250 \mathrm{~mm}$. in length were tested the compressive strength [14], flexural strength [15] and the thermal conductivity [16].

Results were compared with those of the control soil cement brick. The soil cement bricks (RCM) were preparing by varying cement contents with percentage of $8,10,15,20,25,30,35,40,45$ and 50 by dry soil weight at cured times of 28, 60, 90 and 180 days, respectively.

\section{Experimental Result}

\subsection{Physical and Chemical Properties}

The chemical properties of an Eastern Rayong fly ash was investigated by using the X-ray fluorescence (XRF). Results show that there are two oxides such as $\mathrm{SiO}_{2}$ and $\mathrm{CaO}$ which can react with alkyne group of cement. The values are given by $38.47 \%$ and $18.21 \%$ respectively. The local soil from Ratchaburi was also observed these oxides values and given by $82.25 \%$ and $0.34 \%$. The total of main oxides $\left(\mathrm{SiO}_{2}+\mathrm{Al}_{2} \mathrm{O}_{3}+\mathrm{Fe}_{2} \mathrm{O}_{3}\right)$ of fly ash produced from coal (Bituminous) is equal to $71.55 \%$. The particle characterization was tested using the Scanning electron microscope (SEM). It was found that the particle shape of an Eastern Rayong fly ash was the mixing shape between round and angle shapes.

The particle sizes was approximately $32.0 \mu \mathrm{m}$ for Rayong fly ash and $56.47 \mu \mathrm{m}$ for the Ratchaburi local soil, respectively as shown in Table $\mathbf{1}$ and Figure 1. For the local Ratchaburi soil, the plasticity property was tested by according to ASTM D4318 [17]. The results show that the liquid limit (LL) is $14.75 \%$ and the plastic limit (PL) is $15.07 \%$. From these results it can be concluded that this material is Non-Plastic materials (NP).

\subsection{Mechanical Properties}

The compressive strength of soil cement brick (RCM) is compared with soil cement brick with Portland cement type I at a constant content of $5 \%$ mixed by varying fly ash contents of $3 \%, 5 \%, 10 \%, 15 \%, 20 \%, 25 \%, 30 \%$, $35 \%, 40 \%, 45 \%$ and $50 \%$ by dry soil weight basis at cured time of 28 days as shown in Figure 4 . Results show that the compressive strength of soil cement brick with Portland cement content of $8 \%$ (RCM8) is equal to 88.59 $\mathrm{Kg} \cdot \mathrm{cm}^{-2}$ compared with soil cement brick mixed with $3 \%$ fly ash (RYFA5+3) which value is $42.13 \mathrm{Kg} \cdot \mathrm{cm}^{-2}$. According to these values, it shows that the compressive strength of RYFA5+3 is given as $48.40 \%$ of RCM8.

Moreover, soil cement brick with 50\% of Portland cement content (RCM50) compared with soil cement brick mixed with $45 \%$ of fly ash content (RYFA5+45), the compressive strength values are 359.71 and 113.03

Table 1. The chemical property of an Eastern Rayong fly ash and Ratchaburi local soil.

\begin{tabular}{ccc}
\hline \multirow{2}{*}{ Oxides } & \multicolumn{2}{c}{ Raw materials } \\
\cline { 2 - 3 } & Rayong fly ash (\%) & Ratchaburi local soil, (\%) \\
\hline $\mathrm{SiO}_{2}$ & 38.47 & 82.25 \\
$\mathrm{Al}_{2} \mathrm{O}_{3}$ & 25.23 & 12.95 \\
$\mathrm{Fe}_{2} \mathrm{O}_{3}$ & 7.850 & 0.010 \\
$\mathrm{CaO}$ & 18.21 & 0.340 \\
$\mathrm{LOI}$ & 2.390 & 7.310 \\
\hline
\end{tabular}




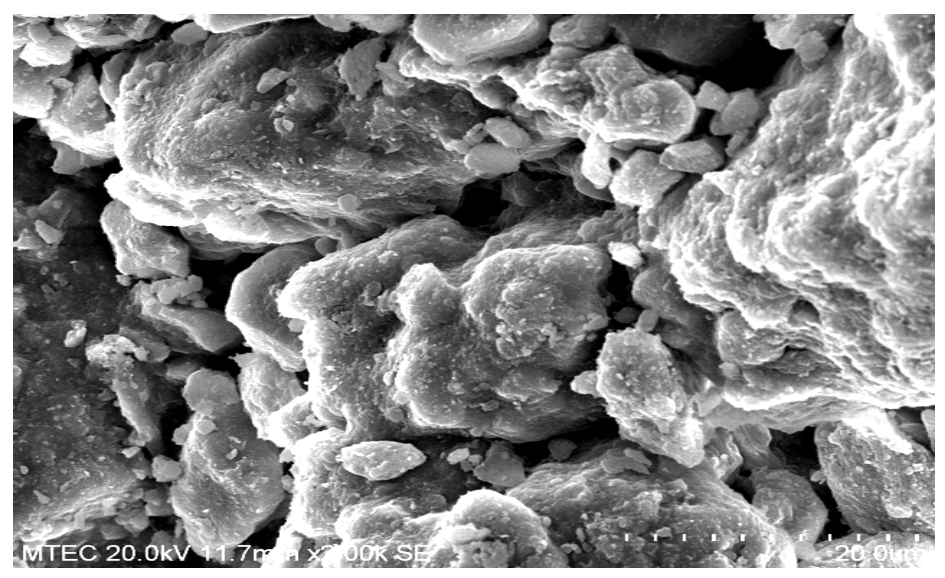

Figure 1. Shows the particle size of Rathaburi local soil using Scanning electron microscope.

$\mathrm{Kg} \cdot \mathrm{cpm}^{-2}$, respectively. This confirms that adding more cement contents can increase the compressive strength as shown in Figure 2, on the other hand, at 28 days cured time, with constant cement content and varying fly ash contents, the compressive strength increases with increasing fly ash contents up to $30 \%$ by weight. Adding more fly ash contents, the compressive strength starts decreasing as shown in Figure 3.

However, according to the standards TIS: 102 - 2517 (Specification for structural clay load-bearing tile) [18] and TCPS: 602 - 2547 (Specification for interlocking block on load-bearing type) [19], it illustrates that the compressive strength of soil cement brick mixed with fly ash qualifies the standards.

The flexural strength on modulus of rupture of these materials are observed and results are given as Figure 4 \& Figure 5. At 28 days cured time, it shows that the modulus of rupture values of RCM8 and RYFA5+3 are 12.91 and $5.95 \mathrm{Kg} \cdot \mathrm{cm}^{-2}$, respectively. Also, the modulus of rupture of RCM50 and RYFA45+5 are 54.15 and $7.96 \mathrm{Kg} \cdot \mathrm{cm}^{-2}$. Comparing of these results show that modulus of rupture of RYFA5+3 is calculated as $46.08 \%$ of RCM8 and RYFA5+45 are calculated as $14.69 \%$ of RCM50.

These confirm that at the same weight, adding more cement contents increase the modulus of rupture which is agreement to the compressive strength property shown previously. With constant cement content, the modulus of rupture is investigated by varying fly ash contents with percentages of 3, 5, 10, 15, 20, 25, 30, 35, 40 and 45 as shown in Figure 5.

At cured time of 28 days, it is found that the maximum modulus of rupture presents at $30 \%$ fly ash contents. Agreement with the compressive strength, adding fly ash contents can increase the modulus of rupture up to $30 \%$ fly ash content. Adding more than these values, the modulus of rupture starts decreasing.

The relationship between the thermal conductivity and cured time of the local soil cement brick and soil cement brick mixed with varying of fly ash contents. Results show that at 28 days, soil cement brick with $8 \%$ cement contents, the thermal conductivity value is $1.4861 \mathrm{~W} \cdot \mathrm{mK}^{-1}$. The thermal conductivity increase with increasing cement contents which the maximum value presents at $50 \%$ cement contents which the value is 2.0553 $\mathrm{W} \cdot \mathrm{mK}^{-1}$ in Figure 6 \& Figure 7.

On the other hand, for soil cement brick mixed with fly ash the thermal conductivity decreases with increasing fly ash content. With fly ash content of $3 \%$ (RYFA5+3), the thermal conductivity value is $1.8938 \mathrm{~W} \cdot \mathrm{mK}^{-1}$ and $0.9762 \mathrm{~W} \cdot \mathrm{mK}^{-1}$ for fly ash content of $45 \%$ (RYFA5+45). This confirms that adding fly ash can improve the thermal conductivity of materials.

Comparison the properties between soil cement brick mixed with fly ash and market products in Figure 8 shows the compressive strengths of three materials which are the soil cement brick mixed with $3 \%$ fly ash content (RYFA5+3) at cured time of 28 days, original red brick and commercial cement block. Results show that the compressive strength of RYFA5+30 is equal to $134.29 \mathrm{Kg} \cdot \mathrm{cm}^{-2}$ which is calculated as $70.89 \%$ of the original red brick and 3.86 times of the commercial cement block.

Also, the modulus of rupture of three materials are compared as shown in Figure 9. For RYFA5+30, the maximum modulus of rupture value is $10.26 \mathrm{Kg} \cdot \mathrm{cm}^{-2}$ which is given as 1.59 times of the original red brick (7.071 $\left.\mathrm{Kg} \cdot \mathrm{cm}^{-2}\right)$ and 3.09 times of the commercial cement block $\left(3.32 \mathrm{Kg} \cdot \mathrm{cm}^{-2}\right)$, respectively. Figure 10 shows that 


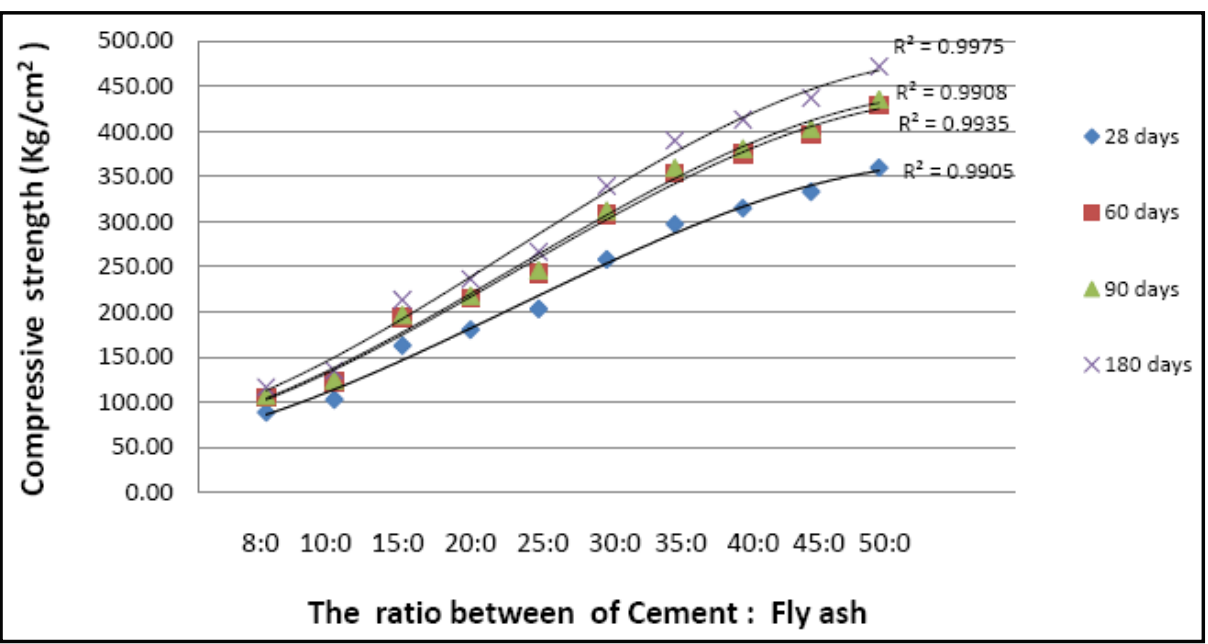

Figure 2. Relationship between compressive strength of local soil cement bricks (control).

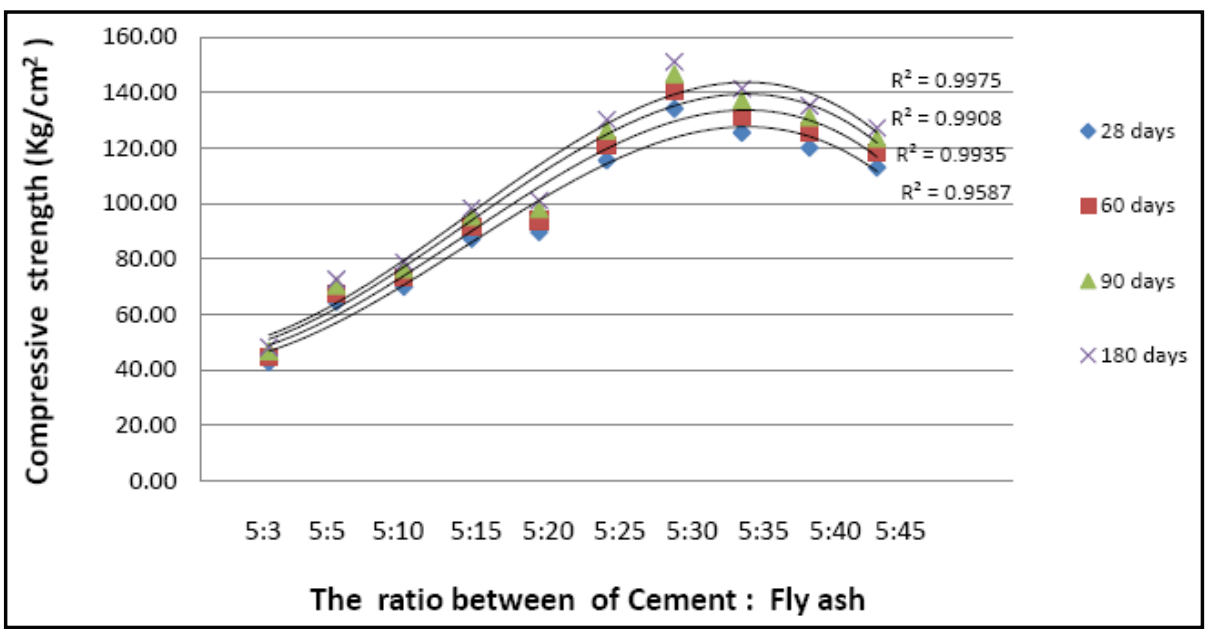

Figure 3. The compressive strength of local soil cement bricks with an Eastern Rayong fly ash source, cured time at $28,60,90$ and 180 days.

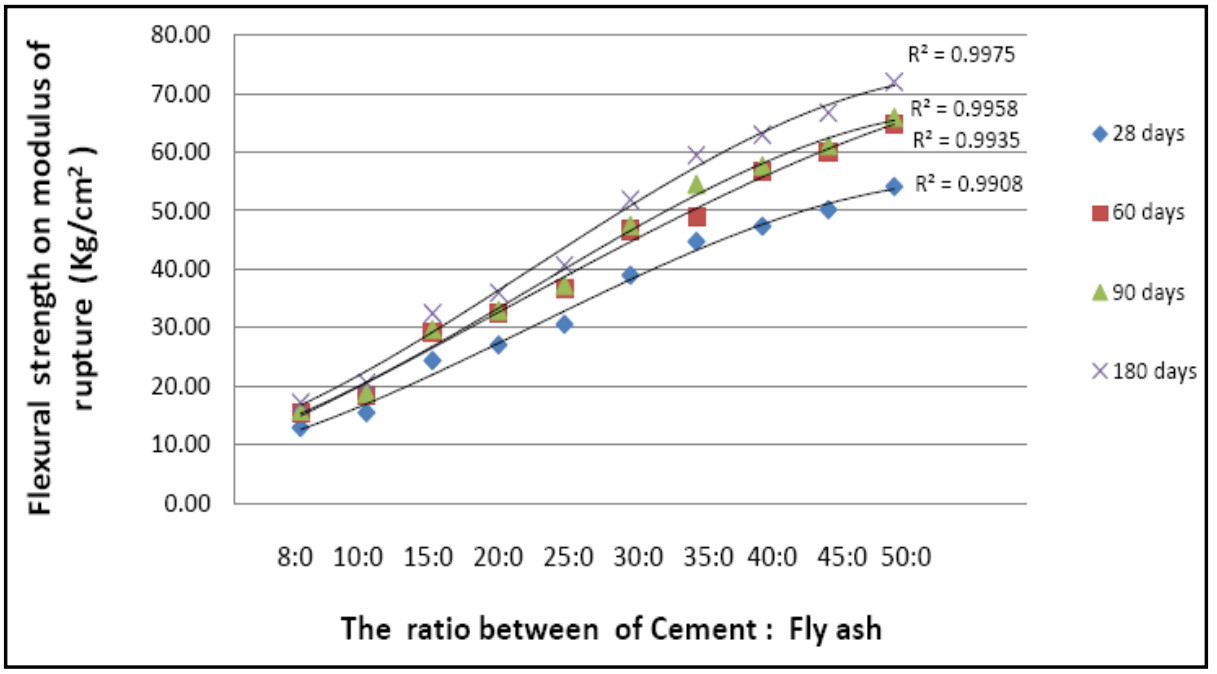

Figure 4. Relationship between the flexural strength of local soil cement bricks (control). 


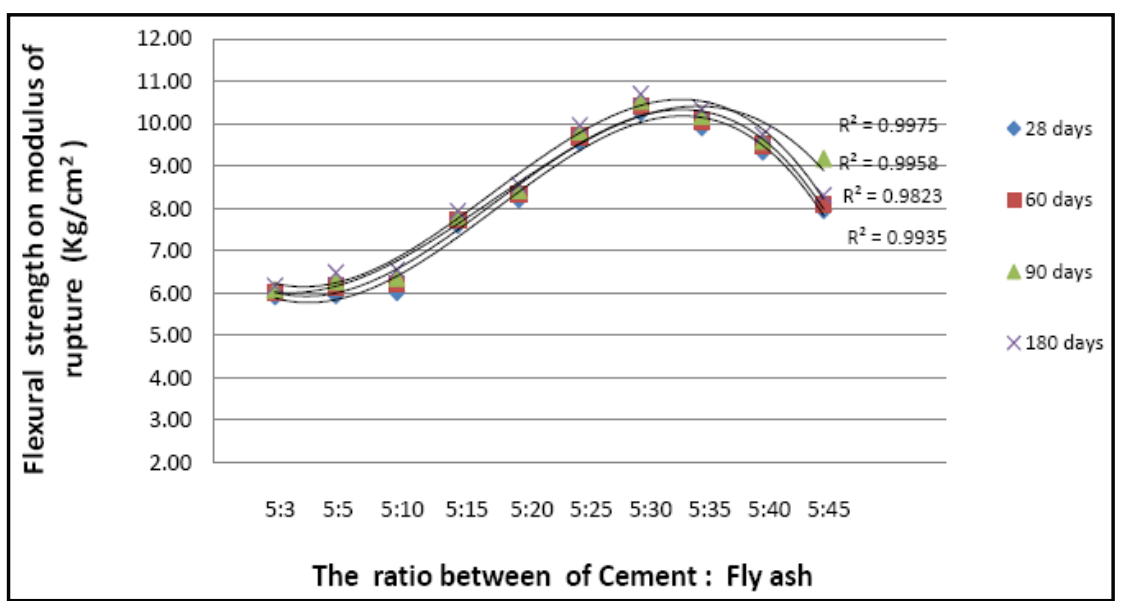

Figure 5. The flexural strength of local soil cement bricks with an Eastern Rayong fly ash source, cured time at 28, 60, 90 and 180 days.

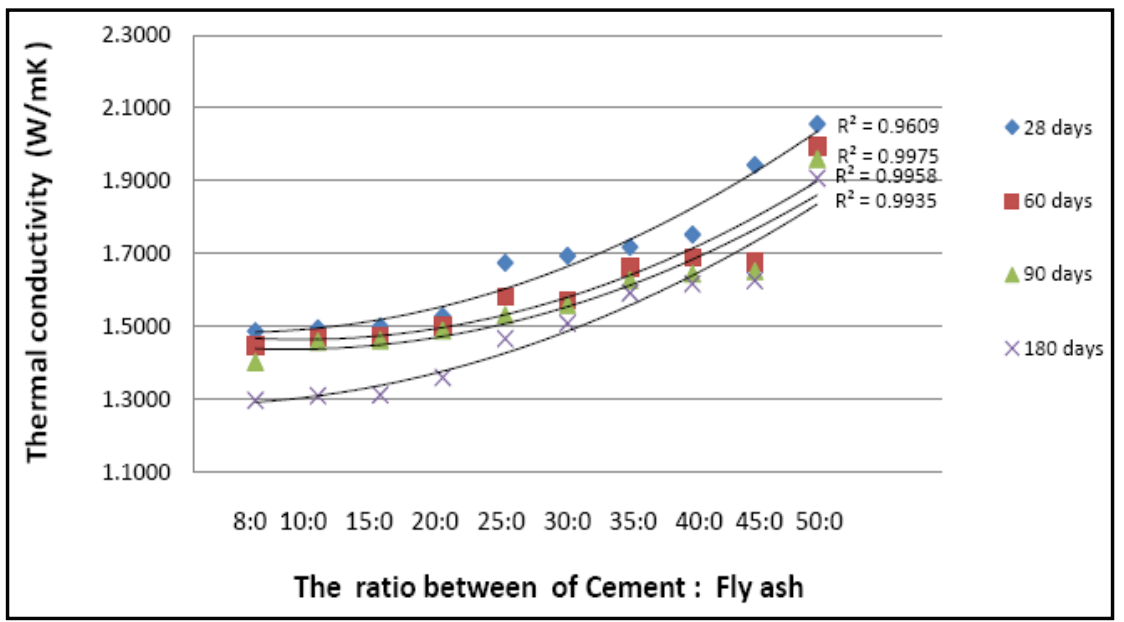

Figure 6. Relationship between the thermal conductivity of local soil cement bricks (control).

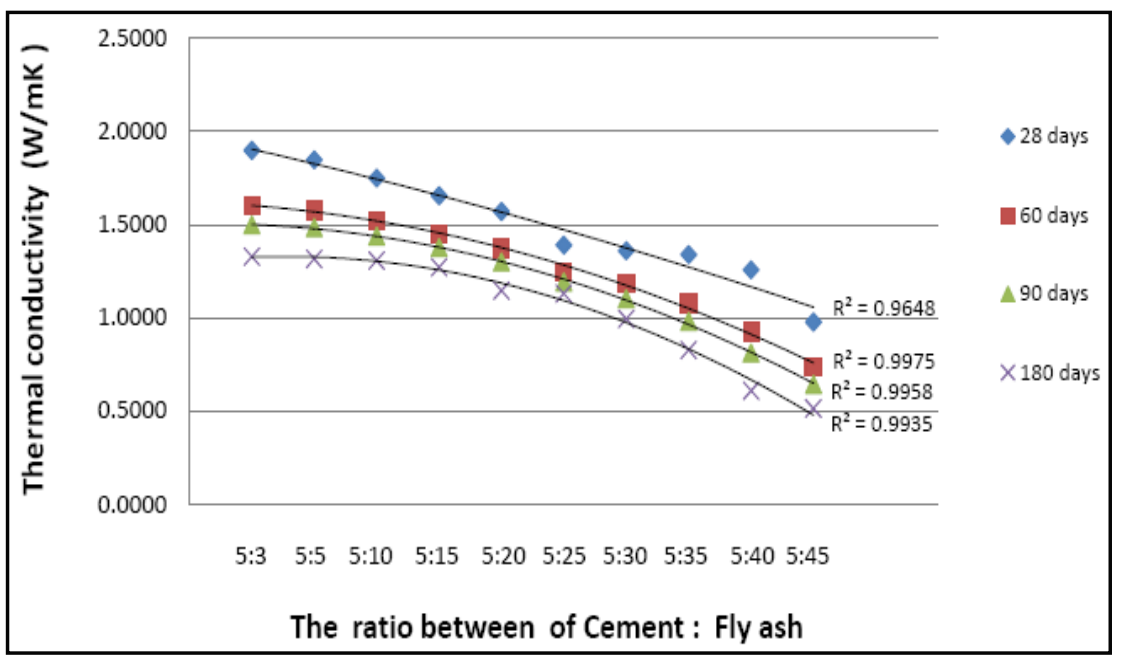

Figure 7. The thermal conductivity of local soil cement bricks with an Eastern Rayong fly ash source, cured time at 28, 60 , 90 and 180 days. 


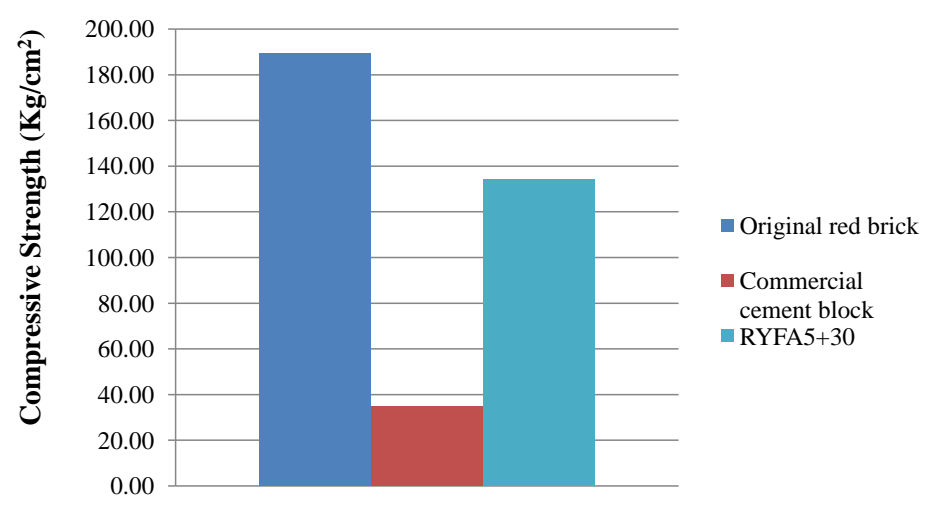

Figure 8. Shows the compressive strength of soil cement brick mixed with 5\% cement contents and Eastern Rayong fly ash source compared with the red brick and commercial cement block.

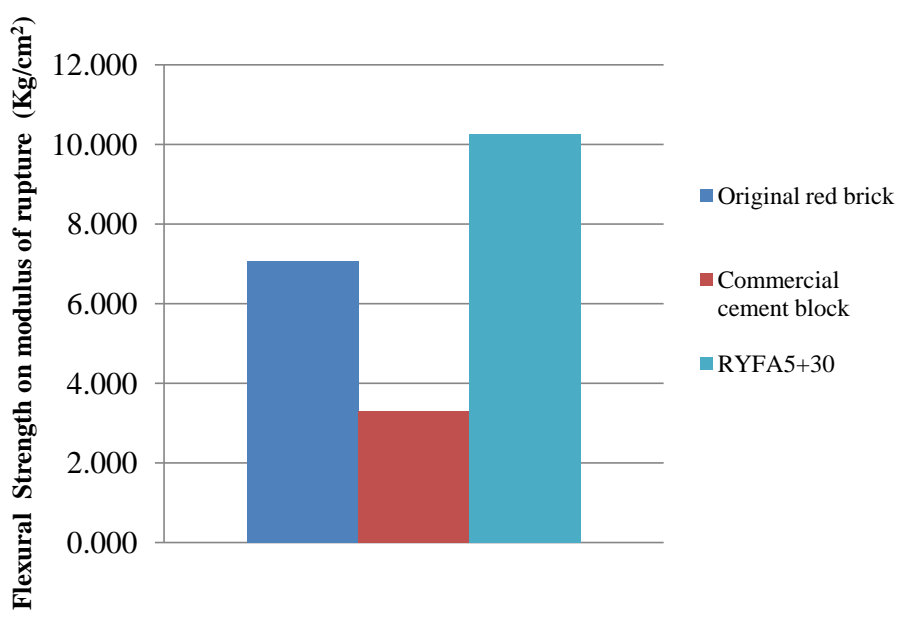

Figure 9. Shows the flexural strength of soil cement brick mixed with 5\% cement contents and an Eastern Rayong fly ash source compared with the red brick and commercial cement block.

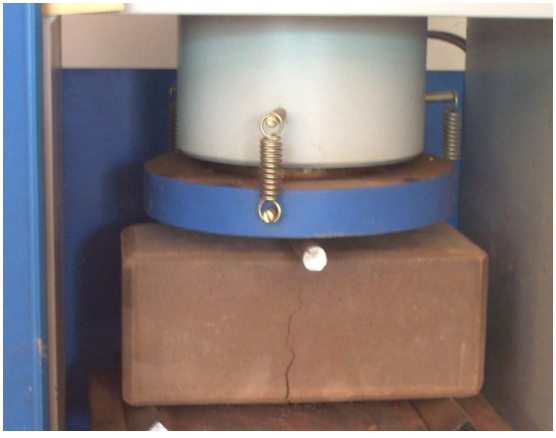

(a)

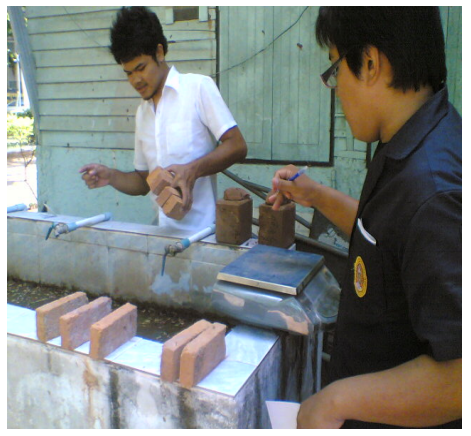

(b)

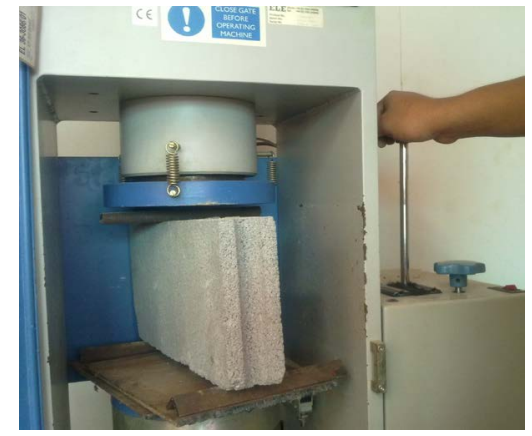

(c)

Figure 10. Shows pictures of the soil cement brick mixed with $5 \%$ cement contents and Eastern Rayong fly ash source (a), the red brick (b) and commercial cement block (c).

the modulus of rupture of soil cement brick mixed with fly ash is higher than those of both commercial products.

Comparison the thermal conductivity of three material types, it is found that at cured time 28 days, RYFA5+ 30 shows the maximum thermal conductivity compared with the rest. The value is $1.35696 \mathrm{~W} \cdot \mathrm{mK}^{-1}$ which is 1.13 times of the original red brick and 4.92 time of the commercial cement block. These results confirm that the thermal conductivity of RYFA5+30 is higher than the original red brick and commercial cement block as shown in Figure 11. 


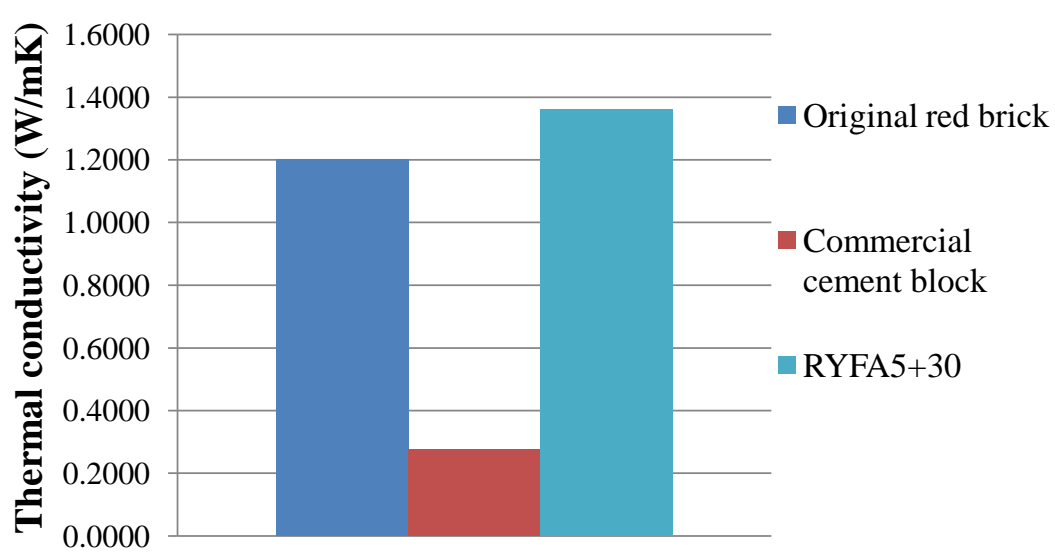

Figure 11. Shows the thermal conductivity of soil cement brick mixed with $5 \%$ cement contents and Eastern Rayong fly ash source compared with the red brick and commercial cement block.

\section{Conclusions}

This study shows that the compressive strength and modulus of rupture of soil cement brick increase with increasing cement content and cured time. On the other hand, for soil cement brick mixed with Rayong fly ash, they increase with increasing fly ash content up to $30 \%$ by weight. Adding more than $30 \%$ these properties start decreasing. However, considered by these properties, it confirms that this material can be used as the structural clay load bearing according to TIS. 102 - 2517 and TCPS.

The thermal conductivity of soil cement brick increases with increasing cement content. Conversely, for of soil cement brick mixed with fly ash, adding more fly ash can decrease the thermal conductivity. Thus, this material can be used in the house which needs to protect the heat from outside. By conclusion, this work shows that adding an Eastern Rayong fly ash in soil cement brick shows enough quality to produce as the structural clay load-bearing tile material and it is clearly seen that the production of material is friendly with the environment and is appropriate to use in the low cost house in the local area of Thailand.

\section{Acknowledgements}

The author would like to express gratitude to researchers, namely Dr. Rattanakorn Rawangkul, STRR Engineering CO., LTD, Thailand, Assoc. Prof. Dr. Wanchai Yodsudjai, Head of Department of Civil Engineering, Kasetsart University, Assoc. Prof. Dr. Trakool Aramraks Department of Civil Engineering, Kasetsart University, Thailand for their invaluable help and constant encouragement throughout this research. Sincere thanks to the Department of Civil and Architecture for instrument test supporting and Muban Chombueng Rajabhat University, MCRU for financial support.

\section{References}

[1] Energy Policy \& Planning office, Ministry of Energy (2011), Thailand.

[2] Kumar, S. (2002) A Perspective Study on Fly Ash-Lime-Gypsum Bricks and Hollow Blocks for Low Cost Housing Development. Construction and Building Materials, 16, 519-525.

[3] Kumar, S. (2003) Fly Ash-Lime-Phosphogypsum Hollow Blocks for Walls and Partitions. Building and Environment, 38, 291-295. http://dx.doi.org/10.1016/S0360-1323(02)00068-9

[4] Chiang, K.-Y., Chou, P.-H., Hua, C.-R., Chien, K.-L. and Cheeseman, C. (2009) Lightweight Bricks Manufactured from Water Treatment Sludge and Rice Husks. Journal of Hazardous Materials, 171, 76-82. http://dx.doi.org/10.1016/j.jhazmat.2009.05.144

[5] Xu, L.L., Guo, W., Wang, T. and Yang, N.R. (2005) Study on Fired Bricks with Replacing Clay by Fly Ash in High Volume Ratio. Construction and Building Materials, 19, 243-247. http://dx.doi.org/10.1016/j.conbuildmat.2004.05.017

[6] Cultrone, G. and Sebastian, E. (2009) Fly Ash Addition in Clayey Materials to Improve the Quality of Solid Bricks. Construction and Building Materials, 23, 1178-1184. http://dx.doi.org/10.1016/j.conbuildmat.2008.07.001 
[7] Demirboga, R. and Gul, R. (2003) The Effects of Expanded Perlite Aggregate, Silica Fume and Fly Ash on the Thermal Conductivity of Lightweight Concrete. Cement and Concrete Research, 33, 723-727. http://dx.doi.org/10.1016/S0008-8846(02)01032-3

[8] Oti, J.E., Kinuthia, J.M. and Bai, J. (2009) Engineering Properties of Unfired Clay Masonry Bricks. Engineering Geology, 107, 130-139. http://dx.doi.org/10.1016/j.enggeo.2009.05.002

[9] Toledo, R., dos Santos, D.R., Faria Jr., R.T., Carrio, J.G., Auler, L.T. and Vargas, H. (2004) Gas Release during Clay Firing and Evolution of Ceramic Properties. Applied Clay Science, 27, 151-157. http://dx.doi.org/10.1016/j.clay.2004.06.001

[10] González, I., Galán, E., Miras, A. and Vázquez, M.A. (2011) $\mathrm{CO}_{2}$ Emissions Derived from Raw Materials Used in Brick Factories: Applications to Andalusia (Southern Spain). Applied Clay Science, 52, 193-198. http://dx.doi.org/10.1016/j.clay.2011.01.003

[11] Alam, S.A. and Starr, M. (2009) Deforestation and Greenhouse Gas Emission Associated with Fuel Wood Consumption of the Brick Making Industry in Sudan. Science of the Total Environment, 407, 847-852. http://dx.doi.org/10.1016/j.scitotenv.2008.09.040

[12] Koroneos, C. and Dompros, A. (2007) Environmental Assessment of Brick Production in Greece. Building and Environment, 42, 2114-2123. http://dx.doi.org/10.1016/j.buildenv.2006.03.006

[13] Namboonruang, W. (2014) Techno-Eco Assessment and Sustainable Development of a Novel "Muban Chombueng Product" of the Local Industries of Thailand. Advanced Materials Research, 953-954, 1505-1508. http://dx.doi.org/10.4028/www.scientific.net/AMR.953-954.1505

[14] American Standard Testing and Materials (1996) Standard C67, Standard Test Methods for Sampling and Testing Brick and Structural Clay Tile. ASTM, West Conshohocken, USA.

[15] American Standard Testing and Materials (1996) Standard C293, Standard Test Methods for Flexural Strength of Concrete (Using Simple Beam with Center-Point Loading). ASTM, West Conshohocken, USA.

[16] American Standard Testing and Materials (1996) Standard C117, Standard Test Methods for Steady-State Heat Flux Measurements and Thermal Transmission Properties by Means of the Guarded-Hot Plate Apparatus. ASTM, West Conshohocken, USA.

[17] American Standard Testing and Materials (1996) Standard D4318, Standard Test Methods for Liquid Limit, Plastic Limit, and Plasticity Index of Soils. ASTM, West Conshohocken, USA.

[18] Specification for Structural Clay Load-Bearing Tile (1994) TIS:102-2517, Bureau of Thai Industrial Standard, Bangkok, Thailand.

[19] Specification for Interlocking Block (Load-Bearing Type) (2004) TCPS: 602-2547, Bureau of Thai Industrial Standard, Bangkok, Thailand. 